\title{
Improvement of grinding technology with vortex cooling of steels that are liable to crack propagation
}

doi:10.2478/mape-2019-0001

Date of submission to the Editor: 04/2019

Date of acceptance by the Editor: 06/2019

MAPE 2019, volume 2, issue 1, pp. 9-23

\section{Tatiana Nikolajevna Ivanova*}

ORCID ID: 0000-0003-2284-2949

Tchaikovsky branch of Federal State Budgetary Educational Institution of Higher Education "Perm National Research Polytechnic University", Russia

Federal State Budgetary Institution of Science "Udmurt Federal Research Center of the Ural Branch

of the Russian Academy of Sciences“, Russia

\section{Witold Biały}

ORCID ID: 0000-0003-2313-0230

Silesian University of Technology, Poland

\section{Victor Nordin}

ORCID ID: 0000-0003-0923-4818

Kaliningrad State Technical University, Russia

\section{INTRODUCTION}

In current conditions, great attention is paid to the quality of parts, which is mainly governed by finish operations of machining, with grinding being most widespread. So, there is no wonder that scientists dedicate their works to research on grinding process. Many aspects of grinding process are studied owing to them (Ivanova T.N., Dolganov A.M.; 2007; Usov A.V., 2015; Dolganov A.M., Ivanova T.N., 2005; Tyuhta A.V., et al., 2016; Zakharov O.V., et al., 2016).

Complexity of grinding process and phenomena entailing it not always allow reaching required technological results, especially while machining surfaces of parts made of tough-to-machine steels, which are liable to crack propagation. All of these things lead to necessity for new technological solutions that allow highly efficient defect-free machining of parts that are liable to crack propagation. This represents scientificpractical problem of great importance.

One of these solutions is research and development of the grinding process using tool with discontinuous cutting surface and vortex cooling. On the one hand, mechanical engineering needs to provide stable quality under high productivity. On the other hand, capabilities of vortex air cooling during grinding are not studied to a sufficient degree. Both of these factors predetermine the necessity in this research and its relevance.

The combination of quality and stability of mechanical properties applies not only to welded but also cast materials (Gajdzik, Piątkowski, 2013; Szczucka-Lasota, Gajdzik, Węgrzyn, Wszołek, 2017). Enterprises include technological aspects in quality systems to obtain higher quality of product - (case study in Gajdzik, Sitko 2014). All

\footnotetext{
*tatnic2013@yandex.ru
} 
information about the applied technology and its changes are composed of components of the knowledge management system (Gajdzik 2008).

\section{ALTERNATIVE MACHINING OF MATERIALS LIABLE TO CRACK PROPAGATION}

Liability to cracking of steel with initial perlite structure (lamellar pearlite, granular perlite, sorbate) is different from steels with initial martensite structure and under low temperatures this steel demonstrates significant plasticity. Cracks can occur in these parts during grinding due to considerable temperature difference along the section, which can cause formation of high temporary internal tensile stress. Therefore, in order to prevent from crack formation, heating rate is limited.

Allowable temperature drop along the section and heating rate depend on the size and the shape of part and mechanical properties of steel. Castings are more susceptible to crack formation than forgings due to small plasticity of steel. At the same time, high-speed steel is more liable to cracking than carbon steel. When castings of medium-carbon construction steel with initial perlite structure are heated to $700^{\circ} \mathrm{C}$, temperature difference along the section should not exceed $300^{\circ} \mathrm{C}$. When the temperature is above $700^{\circ} \mathrm{C}$, most steels acquire significant plasticity and dilatability.

Before phase transformations castings and forgings are kept under the same conditions to equalize temperatures along the section for provision of simultaneous transformation from $\alpha$ - phase to $y$ - phase across the whole volume of the part. Under great temperature drop along the section of the part the transformation $\alpha>Y$ occurs on the surface, specific volume decreases, tensile stress causing crack formation emerges.

Quenched steel is less plastic and has lower thermal conductivity than annealed one, which boosts susceptibility of steel to cracking during grinding. In contrast to annealed steel, when quenched steel is heated up to temperature Ac1, processes of martensite tempering occur. The change of volume under influence of expansion caused by temperature and compression due to martensite tempering depends on carbon content of steel and the progress of the process of carbon formation from martensite. During heating up to temperatures of phase transformations not only compressive, but also tensile stresses can occur on the surface of quenched parts. Quenched parts unlike annealed ones are susceptible to formation of deep cracks.

During cooling process in quenching and after its end steel liability to cracking is governed by heating temperature. Cracks can occur on parts of small size being cooled as high cooling rates cause considerable temperature drop along the section and great internal stress. Moreover, steel with martensite structure has low plasticity. High-carbon steel, which is quenched to martensite, is subject to brittle fracture during expansion test without any significant macroscopic deformation. Cracks can form in this steel even under uniaxial stress condition and under small tensile deformations, which do not take steel out from elastic zone of deformation. Internal stresses (temporary and residual ones)created by quenching are sufficient for brittle fracture of hardened steel even in parts being a few millimeters thick.

Depending on machining modes governing intensity of heat emission in cutting area and the influence of grinding wheel on machined part, structural transformations followed by stresses of different nature can occur in surface layer. For instance, when 
thermally treated steel is grinded it is possible to obtain two types of structural state of surface layer due to presence of highspeed heat source. In the first case, outside layer represents secondary quenched austenite-martensite, which is under lied by zone of secondary tempered metal with troosto martensite and troostite structure. In the other case, (when intensity and tension of heat process are reduced) we can obtain secondary tempered layer, which undergoes all stages of tempering in main structure of martensite quenching. The feature of both cases is the presence of tensile stresses in surface layer. The further reduction of heat process tension leads to absence of any structural transformations. Under the same heat source intensity but different heating and cooling rates, with the latter being increased, minimum temperatures of structural transformations are placed considerably below the $A c_{1}$ point (Ivanova T.N., Dolganov A.M., 2007).

The most popular natural lubricating-cooling fluid is atmospheric air. The surfaces, formed on steel parts during grinding, are oxidized by air oxygen at once: even under room temperature the speed of formation of unimolecular layer of oxides on the metal surface is thousandths of a second.

The oxygen in the air surrounding the tool during grinding prevents small areas of metal contact from turning into a large area of clutching. Newly created surfaces on contact side of a chip and on the part are chemically active and easily welded to the tool even after initial division. The role of oxygen in the air consists in their connection with newly formed metal surfaces that results in decrease in their activity and clutching to tool.

Application of cooled air in grinding process exerts considerable influence over temperature decrease in cutting area. In addition, it depends not only on heat exchange, but also on properties of cold air flow. A film is formed between cutting surface of the tool and machined surface of the material. The stiffness of the film is equivalent to the one of solid body and the film cannot be removed from contact area for the time equal to $10^{-5} \mathrm{~s}$. This film prevents heated sheared layer from welding and sticking to the surface of abrasive. This makes heat energy emitted during grinding to decrease by 1.5-2 times and reduces friction force. Thus, the air itself acts as a lubricating and cooling agent.

The use of wheels with discontinuous work surface is more efficient way to decrease the temperature in grinding area. These wheels have different construction - they can be equipped with ring grooves on face as well as with holes or grooves (radial and inclined ones). Another design of grinding wheel includes abrasive layer placed eccentrically to rotation axis of the tool. These wheels allow grinding with increased cutting modes. They are enough practically feasible in manufacturing and have increased productivity and firmness (Ivanova T.N., Dolganov A.M., 2007, Usov A.V., 2015).

The analysis conducted has demonstrated that existing recommendations for choice of characteristics and construction parameters of the tool reflect particular cases and this restrains wider application of grinding tools with discontinuous work surface. The problem mentioned can be solved by the design of the grinding tool with a direct injection of pressured cooled air in contact area through discontinuous cutting surface, all appropriate safety measures being complied with during maintenance. For successful use of the tool with discontinuous cutting surface and vortex air cooling along with correct combination of properties of grain and bind it is necessary to set 
optimal correspondence between geometric parameters of cutting elements of the wheels and dynamic characteristics of grinding process as well as the design of vortex tubes, which inject cold air in contact zone.

On the one hand, mechanical engineering needs to provide stable quality under high productivity of surface grinding. On the other hand, injection of vortex cooled air in grinding area is not studied to a sufficient degree. Both of these factors predetermine the necessity in this research and its relevance.

\section{THE STUDY OF THERMOPHYSICAL PROPERTIES OF VORTEX AIR COOLING}

The greatest effect of temperature decrease can be reached by injection of cold air flow in cutting area with implementation of vortex effect, which occurs in swirl flow of compressed air originating in vortex tube.

Vortex tube is smooth cylinder pipe equipped with a tangential nozzle, vortex generator, diaphragm with axial hole and throttle, compressed air inlet pipeline and hot air outlet pipeline.

Vortex effect consists in division of swirl flow into two parts inside these tubes. When air goes through the nozzle, intensive circular flow is formed. Axial layers of this flow are significantly cooled and removed through diaphragm hole in the form of a cold stream, while peripheral layers are getting heated and pouring through throttle as hot stream. As throttle is closed, general level of pressure increases and so does cold flow rate under corresponding decrease in hot flow. Peripheral flow has higher temperature than initial flow, while the temperature of central flow is lower.

Let us set $T^{*}$ and $p^{*}$ for total temperature and pressure of compressed air going to the nozzle, $T^{*}$ хол and $p^{*}$ хол, $T_{\text {гор }}^{*}$ and $p^{*}$ гор - for the same parameters of cold and hot streams, respectively. In this case, the effect of cold stream cooling and hot stream warming can be calculated through the following temperature differences:

$$
\Delta T_{\text {хол }}=T^{*}-T_{\text {хол }}^{*} ; \Delta T_{\text {гор }}=T_{\text {гор }}^{*}-T^{*}
$$

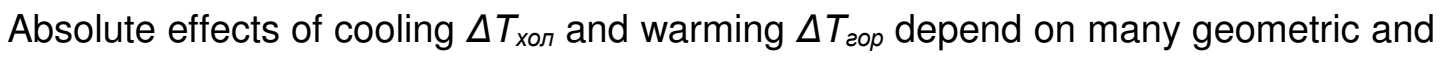
mode parameters. For concrete tube construction and inlet pressure they considerably depend on relative share of cooled stream $\mu$, which is calculated according to mass balance equation for vortex tube.

$$
G_{\text {хол }}=\mu \cdot G ; G_{\text {гор }}=(1-\mu) \cdot G
$$

Operating range of vortex tube varies between $0.2<\mu<0.8$.

According to heat balance equation

$$
\mu \Delta T_{\text {хол }}=(1-\mu) \cdot \Delta T_{\text {гор }}
$$

we can define refrigerating capacity of a vortex tube

$$
q_{\text {хол }}=\mu \Delta T_{\text {хол }} \cdot c_{p}=(1-\mu) \cdot \Delta T_{\text {гор }} \cdot c_{p}
$$

where:

$c_{p}$ - heat capacity of air at constant pressure.

Maximum value of $q_{\text {хол }}$ is reached under $\mu=0.5-0.7$.

Another important characteristic of operation mode of vortex tube is expansion degree, which is determined as ratio of total pressure $p^{*}$ at tube inlet to pressure of fluid $p^{*}$ хол inside which air flows:

$$
\pi^{\prime}=\frac{p^{*}}{p_{\text {хол }}^{*}}
$$


Analysis of equation (5) shows that with growth of $\pi^{\prime}$ cooling effect is increasing, especially in interval $1<\pi^{\prime}<8$. When $\pi^{\prime}>8$ the rate of growth of cooling effect drops. To evaluate efficiency of vortex tube we can consider dimensionless quantities temperature efficiency $\eta_{t}$ and adiabatic energy conversion efficiency (ECE) $\eta_{q}$ :

$$
\eta_{t}=\frac{\Delta T_{\text {хол }}}{\Delta T_{s}^{*}} ; \eta_{q}=\mu \eta_{t}
$$

where:

$\Delta T^{*}{ }_{s}$ - absolute effect from temperature decrease during air expansion from inlet pressure $p^{*}$ to pressure of fluid, inside which air flows:

$$
\Delta T_{s}^{*}=T \cdot\left[1-\left(\frac{1}{\mu^{\prime}}\right)^{0.286}\right]
$$

Maximum values of absolute effects of cooling $\Delta T_{\text {хол }}$ are reached under $\mu=0.2-0.3$, while the highest values of heating effect $\Delta T_{\text {zop }}$ occur when $\mu=0.85-0.95$. Further decreasing of $\mu$ on cold end and its rising on hot end leads to inner reconstruction of the flow (due to the increase of hydraulic resistance of vortex tube) and considerable growth of influence over effects of heat exchange with the environment. To get the minimum value of $p^{*}$ it is necessary to apply $\mu=0.3$, which corresponds to $\eta_{\max }$, while maximum economy occurs when $\mu=0.65$ and is pursuant $(\mu \eta)_{\max }$. What is more, under low ECE vortex tubes demonstrate a wide range of advantages which increase their total efficiency. These advantages include: simplicity and robustness, the absence of moving mechanical parts, the opportunity to carry cooling and heating simultaneously, smooth adjustment of parameters, fast turn-off and turn-in, the opportunity to use different gases under any pressure drops, small size and weight, wide range of air flow rate.

If air is applied as working agent, flow passage area of a nozzle is determined according to equation:

$$
F_{c}=263.16 \cdot \frac{G \sqrt{T^{*}}}{p^{*}}\left[\mathrm{~mm}^{2}\right]
$$

nozzle height will be

$$
h=\sqrt{\frac{F_{c}}{2}}
$$

nozzle width

$$
b=\frac{F_{c}}{h}
$$

vortex tube diameter

$$
D=3.65 \sqrt{F_{c}}
$$

diameter of a hole in the diaphragm

$$
D_{d}=(0.350+0.313 \mu) D
$$

Table 1 shows the results of calculations for vortex tube according to equations (112) under $T^{\star}=20^{\circ} \mathrm{C}$. 
Table 1

Characteristics of vortex tube

\begin{tabular}{|c|c|c|c|c|c|c|c|c|c|c|}
\hline $\begin{array}{c}T_{\text {хол, }}^{*} \\
{ }^{\circ} \mathrm{C}\end{array}$ & $\begin{array}{l}p^{*} \text { хол, } \\
\text { МРА }\end{array}$ & $\boldsymbol{\mu}$ & $\eta$ & $\begin{array}{c}F_{c} \\
M^{2}\end{array}$ & $\begin{array}{c}b, \\
M M\end{array}$ & $\begin{array}{c}\boldsymbol{h} \\
\mathrm{MM}\end{array}$ & $\begin{array}{c}D, \\
M M\end{array}$ & $\begin{array}{l}D_{d,} \\
M M\end{array}$ & $\Pi^{\prime}$ & $\begin{array}{c}\text { G }^{*} \text { хол, } \\
\text { KILOGRAM } \\
\text { FORCE }\end{array}$ \\
\hline 0 & 0.1 & 0.40 & 0.25 & 18.02 & 6.01 & 3.00 & 15.50 & 7.37 & 4 & 0.026 \\
\hline-5 & 0.1 & 0.44 & 0.40 & 13.29 & 5.15 & 2.58 & 13.31 & 6.49 & 3 & 0.009 \\
\hline-2 & 0.09 & 0.22 & 0.76 & 56.32 & 10.61 & 5.31 & 27.39 & 11.47 & 2.2 & 0.025 \\
\hline 0 & 0.3 & 0.43 & 0.40 & 10.51 & 4.59 & 2.29 & 11.83 & 5.73 & 2 & 0.014 \\
\hline-5 & 0.2 & 0.82 & 0.30 & 4.01 & 2.82 & 1.42 & 7.31 & 4.43 & 3 & 0.006 \\
\hline+3 & 0.05 & 0.80 & 0.24 & 12.52 & 5.01 & 2.50 & 12.92 & 7.76 & 5 & 0.007 \\
\hline-10 & 0.05 & 0.40 & 0.40 & 18.68 & 6.10 & 3.06 & 15.78 & 7.49 & 4 & 0.008 \\
\hline
\end{tabular}

Experimental research showed that maximum cooling effect is saved when vortex zone is made in form of conical frustum with expansion towards throttle with a taper angle of $7-10^{\circ}$ and a vortex tube length up to 3 diameters. It allows installation of vortex tubes inside taper cup grinding wheel (Fig. 1) (Dolganov A.M., Ivanova T.N., 2005).

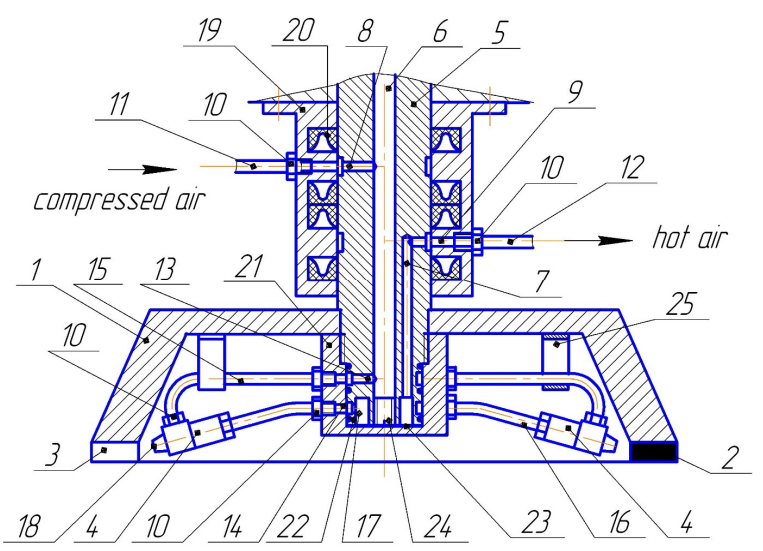

Fig. 1 Grinding wheel with discontinuous cutting surface and vortex air cooling: 1 - body, 2 - abrasive layer, 3 - grooves, 4 - vortex tubes, 5 - moving sleeve, 6 - concentric hole, 7 - hole, 8, 9, 13, 14 - radial hole, 10 - nuts, 11, 12 - pipelines, 15,16 - pipelines, 17 - cavity, 18 - hole, 19 - coupling, 20 - sealing collar,

21- threaded coupling, 22 - sealing rings, 23 - gasket, 24 - screw, 25 - clamps

In abrasive layer of the tool there are grooves of variable cross section, narrowing down towards external surface of the body. The depth of the grooves, made with uniform pitch, corresponds to the thickness of abrasive layer. Thus, cutting surface of the tool is divided into cutting protrusions and grooves. In such a tool forced cooling of cutting zone itself, cutting edges of tool and machined surface is carried out. Maintenance of vortex tubes, their robustness, simple obtaining of cooled air flow, production efficiency of obtaining of cold flow allow us to solve the problem of grinding zone cooling without application of conventional cooling-lubricant fluids.

The main feature of grinding of tough-to-machine materials that are liable to crack propagation by tool with discontinuous cutting surface and cold air feed consists in shifting of optimal granularity range towards greater values in comparison with wheels with continuous cutting surface and cooling-lubricant fluids injection. That is why stronger grains are used.

Formation of grinding temperature depends on operation time of the source. There 
are two possible stages of wheel operation: heating due to abrasive areas and cooling because of grooves on cutting layer of the wheel. By interrupting the process of grinding and supplying additional cooling to grooves to decrease the temperature of the surface, we can limit maximum temperature in contact area between grinding wheel and machined part. Dependence of temperature in grinding zone of tool with discontinuous cutting surface and vortex cooling will be (Ivanova T.N., Dolganov A.M., 2007):

$$
T=\frac{2 q a}{\pi \lambda v} N(D, H) \cdot \mathrm{B}(\mathrm{X}, Z) \cdot \mathrm{K}_{\text {огр }} \int_{Z-H}^{Z+H} \exp (-\xi) K_{0}\left(\sqrt{X^{2}+\xi^{2}}\right) \cdot d \xi
$$

where:

$\mathrm{B}=1-(\beta) \frac{\int_{0}^{\infty} \exp ((-\beta) X) K_{0}\left(\sqrt{X^{2}+Z^{2}}\right) d X}{K_{0}(Z)}-$ coefficient characterizing the influence of heat removal on free surface from the part,

$\beta=\frac{2 q \alpha}{\lambda v},-$ complex of heat exchange;

$U$ - the speed of displacement of part,

$X=\frac{v x}{2 \alpha}$

$Z=\frac{v Z}{2 \alpha^{\prime}}$

$H=\frac{v h}{2 \alpha}$,

$D=\frac{v d}{2 \alpha}$,

$\frac{v\left(z-z^{\prime}\right)}{2 a}=\xi$,

$K_{0}-$ Bessel function of the second kind of order zero,

$\mathrm{x}, \mathrm{z}, \mathrm{z}^{\prime}$ - coordinates of displacement of part,

$h$ - half width of part,

$d$ - thickness of part,

$q$ - heat flow intensity,

$\alpha$ - heat exchange coefficient.

Solving equation (13), heating and cooling speed can be calculated for every point on the surface and inside of part made of steels that are liable to cracking by changing machining modes and intensity of heat source - grinding wheel (Fig. 2).

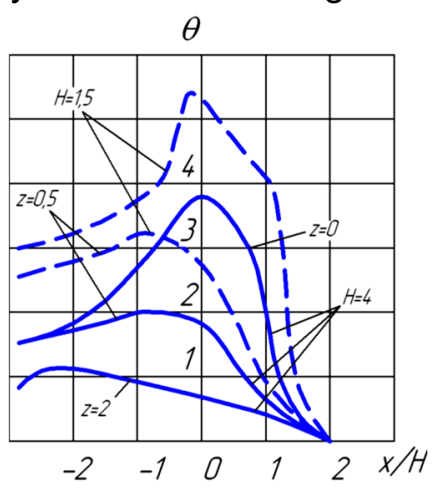

Fig. 2 Dependence of non-dimensional temperature $\Theta$ on $X / H$ on different depth from the surface

The analysis of graphic dependence (Fig. 2) shows that by increasing Htemperature rises and its maximum value moves towards direction which is opposite to heat source movement. As the depth of layer grows, temperature decreases. The greater depth 
of the layer is, the more intensively maximum temperature shifting to direction which is opposite to heat source movement occurs, with speed of heat processes slowing down.

By decreasing $H$ under constant halfwidth of the source $h$ we observed temperature fall and displacement of maximum value point to the middle of the source due to drop of speed of the partu (Fig. 3). An increase in $H$ leads to growth of heat source action and, consequently, causes decrease in speed of heat processes on every depth of surface layer.

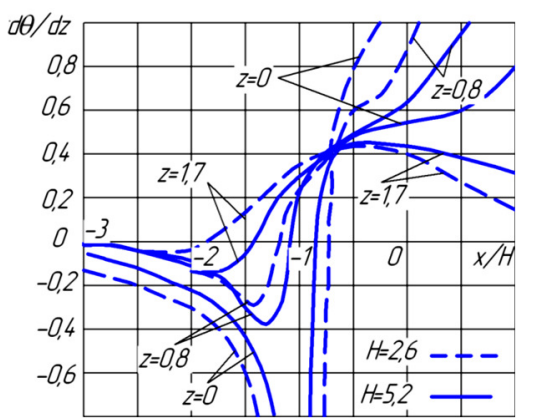

Fig. 3 Dependence of heating depth on non-dimensional half width of source

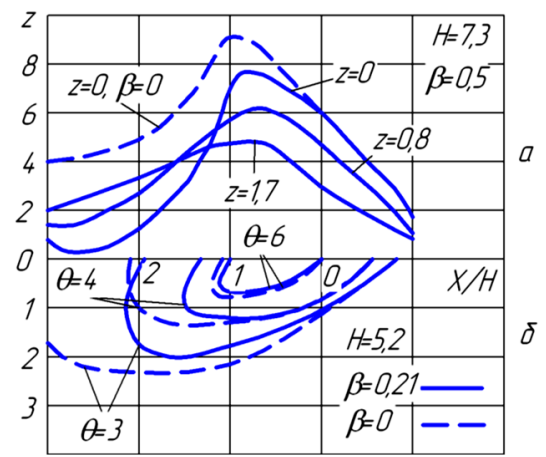

Fig. 4 Dependence of non-dimensional temperature

(a) and heating of surface layers

(b) in presence of heat exchange with cooling fluid

During grinding with cooling heat content of surface layer drops. Considerable fall of temperature of the source is observed along with decrease in temperature of machined surface under great $\beta$ and small speed of part (Fig. 4).

The nature of temperature changing in time after ending of heat source action causes changes of temperature field character along the depth of surface layer. Under the same parameters of heat source and its speed the maximum depth of heating of the surface layer $Z$ to a given temperature is always lower in case of cooling. The application of vortex cooling reduces heating speeds and increases cooling ones not only outside the source but under it too. The closer considered point to back edge of the source is, the more intensively this process occurs decreasing cooling speed outside the source.

The speed of temperature changing is of highest importance in case of maximum longitudinal displacement of the part, i.e. when time of source actiont is minimal and, consequently, great thermal stresses are expected to happen in surface layer. As trises, temperature gradient falls and stresses will decrease. With further growth of $T$ 
the part is exposed to higher temperature and surface layers are heated to greater depth. It results in creation of favorable conditions for stress relaxation process.

Fig. 5. demonstrates graphs of distribution of residual stresses, occurrence depths $h$, the depths of occurrence of defective layer $H$ with changed structure in surface layer of sample being machined according to speed of part.

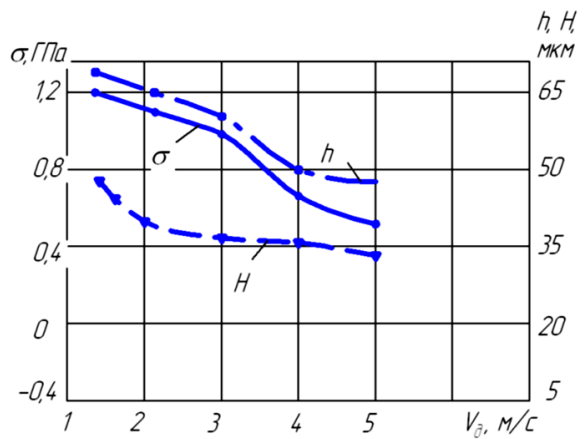

Fig. 5 Dependence of stress $\sigma$, the ir occurrence depth hand defective layer depth $H$ on speed of partudunder $\mathrm{k}_{\mathrm{kp}}=\mathbf{5 0} \mathrm{mps}$

With growth of $U_{\partial}$ decrease in maximum values of residual stress $\sigma$, their occurrence depth $h$ and defective layer depth is observed. Values of $\sigma, h, H$ reduce the most intensively under $U_{\partial}=1-4 \mathrm{mpm}$. It is explained by the fact that with increase in $v_{\partial}$ the time of action of heat source drops, temperature in grinding area falls and temperature field concentrates in thin surface layer of part.

The character of changes in stress $\sigma$ and temperature $T$ is identical, the decrease in their values is observed as ratio $U_{k p} / U_{\partial}$ reduces (Fig. 6). Further decrease in $U_{k p} / U_{\partial}$ to 1-3 almost does not change residual stresses oand temperature in contact area $T$, yet it causes growth of roughness of machined surface. The study of structure of surface layer showed that micro distortions have values which are close to parameters of main structure of metal.

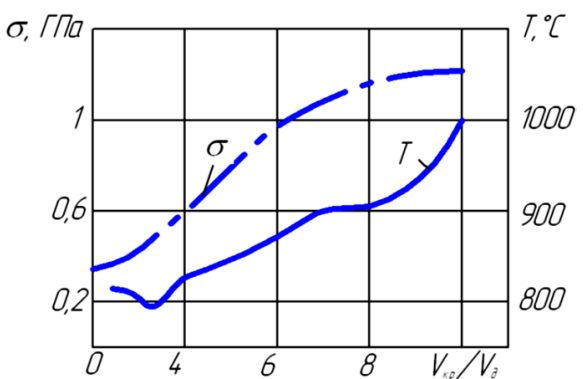

Fig. 6 Dependence $\sigma$ and contact temperature $T$ on ratiou ${ }_{\mathrm{kp}} / U_{\partial}$

An increase in wheel speed from 25 to $50 \mathrm{mps}$ does not change shapes of curves. But it leads to growth of maximum values of residual stresses, which reached the values that are commensurate to ultimate strength of machined material on the depth 10-15 microns. In this case, the depth of tensile stress increased to 52 microns. Metallographic studies established that under $U_{\kappa p}=58 \mathrm{mps}$ tempering burnings occurred on the surface of machined sample, causing formation of defective layer with changed structure. Thus, in case of grinding of steel 12H2MFA (12X2MФA) we can 
achieve minimum values of residual stresses by selecting optimal ratio of the speeds of the wheel and part.

\section{DETERMINATION OF OPTIMAL CONDITIONS OF GRINDING PROCESS WITH APPLICATION OF TOOL WITH DISCONTINUOUS CUTTING SURFACE AND VORTEX COOLING}

Experimental research on cutting forces, roughness, productivity and consumption of wheel grains according to machining modes and tool characteristics allowed us to explain advantages of grinding by tool with discontinuous cutting layer and with vortex air cooling of cutting area.

The decrease in cutting force during grinding by tool with discontinuous cutting surface and with vortex air cooling is explained the following way (Fig. 7).

a)

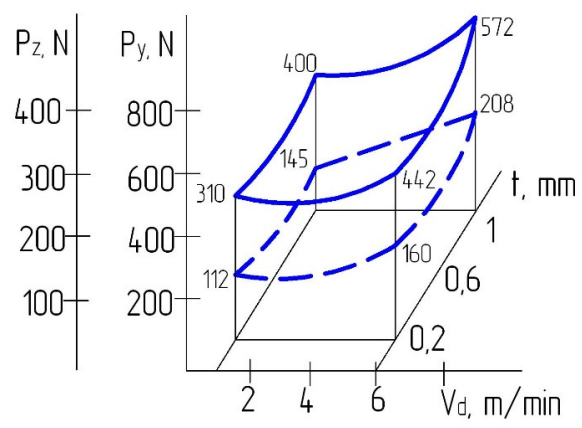

b)

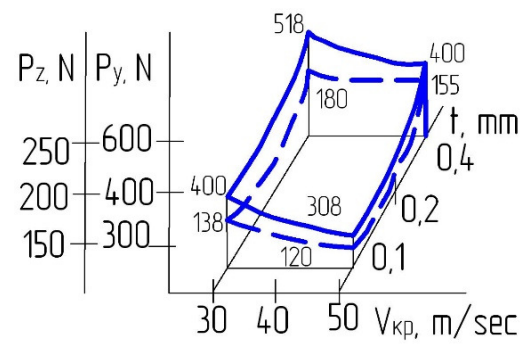

Fig. 7 Dependence of cutting forces on grinding modes with tool of discontinuous cutting surface and vortex cooling a) $v_{\mathrm{kp}}=40 \mathrm{mps}$, b) $v_{\mathrm{A}}=2 \mathrm{mpm}$.

Solid line - $P_{y}$, dash line - $P_{z}$ Machined material - steel 12H2MFA (12X2MФA), wheel АЧК 150x32×40 AC6 100/80-M04-4

Machining allowance during surface grinding is mainly removed by the area of work surface which is adjacent to external diameter. The presence of grooves on work surface leads to increase in the number of cutting edges. It creates better conditions for grains operation as there is no need in initial pressing of grains, machining allowance is distributed more uniformly between separate grains. This all contributes to decrease in cutting forces. In case of grinding by proposed tool, edges of grooves scrape the chip, it accumulates in these grooves and then it is blown away by air flow without blocking the pores. As a result, intensity of smearing process decreases sharply and cutting properties of wheel are saved the same for a long time. The greater grinding depth and speed of part are, the more considerable influence is exerted by mentioned facts. By increasing the velocity of air flow from grooves of tool to $10 \mathrm{mps}$, wheel smearing, friction coefficient and power supplied to grinding are considerably reduced. It also leads to decrease in heat density of grinding process as well as cutting force. It is achieved due to creation of better conditions for cold air feed and removal of cuttings from work zone. Cooled air allows grains of grinding tool to work under considerable loads and it also consumes the heat generated in area of contact between grinding wheel and machined material. That is why there is lower temperature in plane of contact between grinding wheel and machined surface. The bond between grinding tool and vortex cooling is protected from thermal destruction and therefore it firmly holds the grain for a long time, saving its stable cutting 
properties. It reduces the temperature and cutting forces allowing intensification of machining modes.

Fast rotating grinding tool with vortex cooling has bigger cutting ability. As a result, metal layer on every elemental area of machined surface is completely cut off during the contact with the wheel and low roughness is formed, the microhardness increases. The growth of cutting ability of wheel allows us to increase the productivity of machining and decrease specific wear of tool with discontinuous cutting surface and vortex cooling.

As we can see from graphic dependences (Fig. 8), the value of $R_{a}$ grows with increase in longitudinal feed. However, absolute value $R_{a}$ during work with tool with discontinuous cutting surface and vortex cooling is $30-40 \%$ less than the one of tool with continuous cutting surface and it also $10-20 \%$ lower than the one of with tool with discontinuous cutting surface and cooling-lubricant fluid injection from the inside of the wheel. This phenomenon can be explained by more sharp grains of tool with vortex cooling and efficient influence of cooled air on cutting process, which leads to creation of more stable cutting profile and decrease in friction forces.

Cutting contour of fast rotating grinding tool with vortex cooling has high cutting ability, as a result, metal layer on every elemental area of machined surface is completely cut off during the contact with the wheel and low roughness is formed. Grains are loaded more uniformly. This contributes to lasting maintenance of their correct shape. Owing to an increase in cutting ability of the wheel its specific wear during grinding with tool of continuous cutting surface decreases by $10-12 \%$, while in case of tool with discontinuous cutting surface and cooling-lubricant fluid injection it is reduced by 15 $18 \%$. When cold air is supplied, the wear drops by $20-25 \%$.

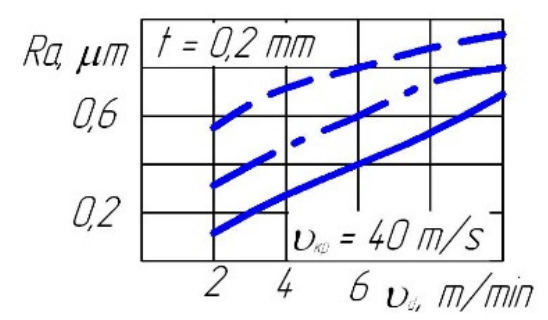

Fig. 8 Dependence of micro roughness height $R a$ on speed of part made of steel 12X2MФA with cooling:

solidline - tool with discontinuous cutting surface and vortex cooling, dashline grinding wheel with continuous cutting surface and cooling-lubricant fluid pouring, dash-and-dot line - tool with discontinuous cutting surface and cooling-lubricant fluid injection from the inside of the wheel

Graphs of micro hardness changing along the depth of surface layer demonstrated that process of grinding by tool with discontinuous cutting surface and vortex cooling causes the least micro hardness change. Grinding by continuous tool is entailed by strengthening of thin surface layer from initial micro hardness $9000-9500 \mathrm{~N} / \mathrm{mm}^{2}$ to $8000-8500 \mathrm{~N} / \mathrm{mm}^{2}$. It is connected with the fact that with increasing time of source operation on surface layers work conditions of the wheel worsen, temperature in zone of contact between continuous grinding wheel and part grows. The similar increase in micro hardness is caused by growth of grinding depth. In case of grinding by tool with discontinuous cutting surface and cooling-lubricant fluid injection the temperature from heating depth of surface layer is removed both in underlying and upper layers. 
As a result, cooling occurs faster on some depth rather than on the surface. If grinding depth ist $=0.2 \mathrm{~mm}$, micro hardness grows with the depth of structurally changed layer $\mathrm{h}$ being increased (Fig. 9). During grinding by discontinuous cutting surface and vortex air cooling the same dependence occurs under smaller depth of structurally changed layer.

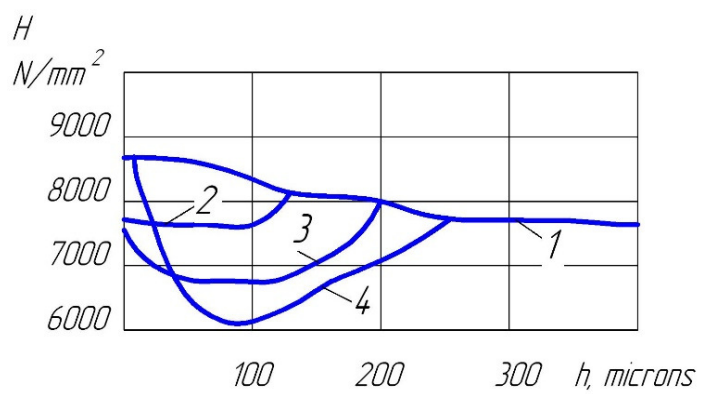

Fig. 9 Chage of micro hardness in surface layer of steel grade 12H2MFA (12X2MФA): 1 - initial, 2 -tool with discontinuous cutting surface and vortex air cooling, 3 - the same tool with cooling - lubricant fluid injection, 4 - tool with continuous cutting surface and cooling-lubricant fluid pouring. $v_{\mathrm{kp}}=40 \mathrm{mps}, v_{\mathrm{A}}=3.0 \mathrm{mpm}, \mathrm{t}=0.2 \mathrm{~mm}$.

As a result of studies of physical-mechanical state of surface layer of machined part, we obtained curves, which characterize micro hardness and allow identification of rational grinding modes in terms of the quality of the surface layer. The study of microstructure during grinding of steels, which are liable to crack propagation, with application of vortex cooling showed full identity of surface layer structure and phase composition with deeper layers.

To introduce the tool with discontinuous cutting surface and vortex air cooling to industrial use it is necessary to select and substantiate optimal grinding modes which allow provision of maximum productivity of machining with compliance of quality requirements of resulting surfaces. As a result of the research, we obtained response surfaces in optimum area by means of two-dimensional section (Fig. 10).

For example, if grinding depth is $0.2 \mathrm{~mm}$ we can obtain roughness $\mathrm{Ra}=0,32$ microns under the following modes: ид $=2.0 \mathrm{mpm}$, икр $=38 \mathrm{mps}$ or ид $=4.0 \mathrm{mpm}$, икр $=27,6$ mps (Fig. 10a). In first case grain consumption will be qал $=0.65 \mathrm{mg} / \mathrm{g}$, while temperature in grinding area $\mathrm{T}=275^{\circ} \mathrm{C}$, in the second case qал $=0,87 \mathrm{mg} / \mathrm{g}, \mathrm{T}=$ $200^{\circ} \mathrm{C}$, respectively. If grinding depth is increased to $0.4 \mathrm{~mm}$ (Fig. 10b) the similar roughness of the surface can be obtained under the next modes:uд $=3,0 \mathrm{mpm}$, икр $=38 \mathrm{mps}$. Then grain consumption will reach qал $=0.84 \mathrm{mg} / \mathrm{g}$, while temperature in grinding area will be $\mathrm{T}=300^{\circ} \mathrm{C}$.

The analysis of equal response lines gives a possibility to show the character of changes in response function in case of variation of different factors. It also lets us find optimal solutions if there are several parameters of optimization. By overlapping sections, we can choose such a combination of grinding modes of tool with discontinuous cutting surface and vortex air cooling, which will ensure solution of optimization problem of technological process of machining. 
a)

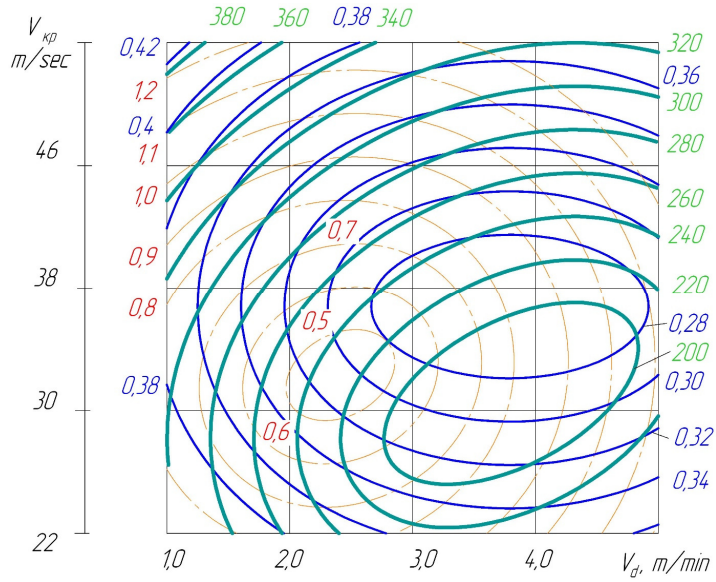

b)

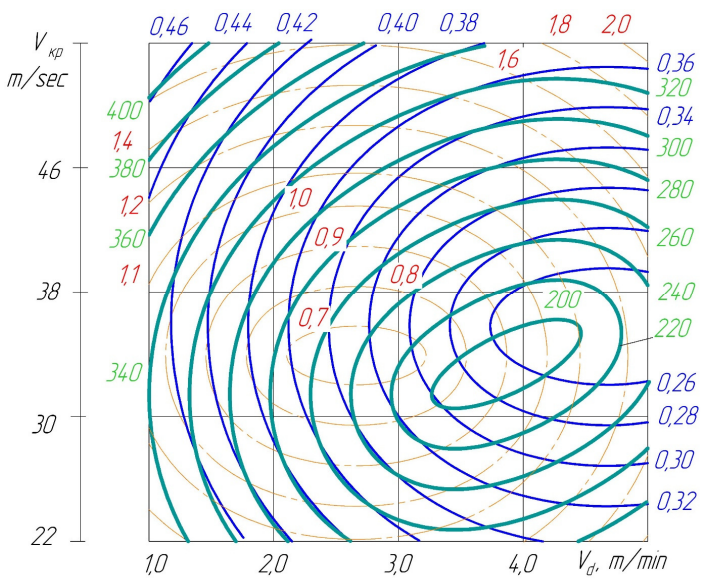

Fig. 10 Two-dimensional sections of response surfaces solid line - roughness $R_{a}$, microns; dash-dot line - tangential force of cutting $P_{z}$, $\mathrm{H}$; dash line - consumption of grains $q_{\text {aл }}$ for grinding depth;

a) $t=0.2 \mathrm{~mm}$, b) $t=0.4 \mathrm{~mm}$

Theoretical and experimental research and industrial introduction of highly efficient grinding method showed that grinding by wheels with discontinuous cutting surface and vortex air cooling of cutting zone provides considerable increase in productivity and enhance the quality of machined steel which are liable to crack propagation.

\section{CONCLUSIONS}

As a result of conducted complex of studies, relevant science-technical problem of increasing of efficiency of grinding process was solved due to application of tool with discontinuous cutting surface and vortex air cooling of cutting zone during machining of surfaces of steels liable to cracking. On the base of carried research, the following conclusions can be made:

1. Conducted analysis of features of grinding process of steels that are liable to crack propagation showed that decrease in heat density of the process can be provided by wheels with discontinuous cutting surface and vortex air cooling.

2. The study of heat generation during machining by tools with discontinuous cutting surface and vortex air cooling was carried out. Obtained thermophysical parameters of vortex air cooling (increase in speed of stream flowing, expansion degree, share of cold stream and decrease in humidity of air stream) allow reducing heat density due to growth of cooling effect in grinding zone. Maximum cooling effect is achieved when mass fraction of the cold stream is 0.25 . In case of further 
increasing of mass fraction of cold stream cooling effect drops and totally disappears when it is equal to 1 . Cooling effect rises significantly with the growth of expansion degree of vortex air flow, especially in the interval 1-8 and in case of drop of pressure of cold stream. Under further increasing of expansion degree or growth of air humidity the rate of cooling effect increase falls.

3. New guidelines developed for tool with discontinuous cutting surface and vortex air cooling allow decreasing of temperature in contact area between the tool and machined surface due to supplying of cold air flow from the inside of the tool into the grooves of the cutting surface of the wheel. It was established that the most intensive decrease in temperature of machined surface is achieved by increase in groove length, amount of vortex tubes and speed of vortex air flow. Maximum cooling effect is achieved when cross-section of the groove is narrowed down in the direction of the flow of air from the tool.

4. Complex research on functional (force and temperature) and outlet (roughness, microhardness of machined surface) parameters of grinding process carried out by tool with discontinuous work surface and vortex air cooling was conducted. Variable characteristics in technological conditions occurring in case of machining of steels, which are liable to crack propagation, were also studied. The results of the research demonstrated considerable technological advantages of developed construction of tool in terms of stabilization of functional and outlet parameters of grinding process.

5. On the base of experimental studies we developed recommendations for choice of optimal grinding modes by tool with discontinuous cutting surface and vortex air cooling of flat parts made of steels being liable to cracking. It was established that roughness $R_{a}=0.10-0.30$ microns can be obtained when speed of part is $U=1.0$ $4.0 \mathrm{mpm}$, the depth is $t=0.1-0.4 \mathrm{~mm}$ and wheel speed is $U_{k p}=20-50 \mathrm{~m} / \mathrm{s}$.

\section{REFEENCES}

Gajdzik, B. (2008). Concentration on knowledge and change management at metallurgical company. Metalurgija 47(2) pp. 142-144.

Gajdzik, B, Sitko, J. (2014). An analysis of the causes of complaints about steel sheets in metallurgical product quality management systems. Metalurgija. 53(1) pp. 135-138.

Piątkowski, J, Gajdzik, B. (2013). Testing phase changes in Al-Si alloys with application of thermal analysis and differential calorimetric analysis. Metalurgija (52)4, pp. 469-472

Szczucka-Lasota, B. Gajdzik, B., Węgrzyn T., Wszołek, Ł. (2017). Steel Weld Metal Deposit Measured Properties after Immediate Micro-Jet Cooling. Metals, 7(9), 339; https://doi.org/10.3390/met7090339

Ivanova, T.N., Dolganov, A.M. (2-07). The modern snap in technology of diamond face grinding of flat surfaces. Monograph. Izhevsk: Institute of Economics UrB RAS Publ, pp. 387.

Patentforinvention, 2307729/MПКВ24D 7/10, B24B 55/02 Grinding tool with vortex cooling/Dolganov A.M., Ivanova T.N./Russia/2005140684/02 decl. 26.12.2005 publ. 10.10.2007. Bul. № 28.

Tyuhta, A.V., Vasilenko, Y.V. and Kozlov A.M., Ways to Enhance Environmental Flat Grinding by Improving the Technology of the Coolant Supply. Procedia Engineering, 150(2016), pp. 1073-1080.

Usov, A.V. (2015). Research of reasons of formation of cracks at polishing of materials and alloys, apt to this type of defects. Technologes of informations are in education, science and production, 3(8) pp. 117-133.

Zakharov, O.V., Khudobin, L.V., Vetkasov, N.I., Sklyarov I.A. and Kochetkov A.V. (2016). Abrasive-Jet Machining of Large Hollow Components. Russian Engineering Research, 36(6), pp. 469-471. 
Abstract. Complexity of grinding process and phenomena entailing it not always allow reaching required technological results, especially while machining surfaces of parts made of tough-to-machine steels, which are liable to crack propagation. Cracks can occur in these parts during grinding due to considerable temperature difference along the section, which can cause formation of high temporary internal tensile stress. Application of cooled air in grinding process exerts considerable influence over temperature decrease in cutting area. In addition, it depends not only on heat exchange, but also on properties of cold air flow. The greatest effect of temperature decrease can be reached by injection of cold air flow in cutting area with implementation of vortex effect, which occurs in swirl flow of compressed air originating in vortex tube. The study of heat generation during machining by tools with discontinuous cutting surface and vortex air cooling was carried out. Obtained thermophysical parameters of vortex air cooling (increase in speed of stream flowing, expansion degree, share of cold stream and decrease in humidity of air stream) allow reducing heat density due to growth of cooling effect in grinding zone. On the base of experimental studies we developed recommendations for choice of optimal grinding modes by tool with discontinuous cutting surface and vortex air cooling of flat parts made of steels being liable to cracking.

Keywords: steel, grinding, temperature, vortex cooling, wheel 